\title{
Yaşam Boyu Öğrenme Kurslarında Yabancı Dil Olarak Türkçe (Edinburgh Üçüncü Yaş Üniversitesi Örneklemi)
}

Serpil ÖZDEMiR, Yrd. Doç. Dr. Bartın Üniversitesi Eğitim Fakültesi, serpilozdemir34@gmail.com

Öz: Bu araştırmanın amacı Edinburgh Üçüncü Yaş Üniversitesinde yabancı dil olarak Türkçe öğrenenlerin öğrenme nedenlerini, Türkçelerini geliştirmek için nelere ihtiyaç duyduklarını, hangi dil becerilerini geliştirmek istediklerini, Türkçe hakkında düşüncelerini ve Türkçe öğrenenlerin artması için yapmamız gerekenler konusunda önerilerini belirlemektir.

Araştırma durum çalışmasıdır. Veriler yarı yapılandırılmış görüşme formu ve gözlemlerle elde edilmiştir. Veriler betimsel analizle çözümlenmiştir. Araştırmanın örneklemi Edinburgh Üçüncü Yaş Akademisidir.

Grubun Türkçe öğrenme amacı Türklerle iletişim kurmaktır. Grup üyeleri, Türkçeyi zor bir dil olarak değerlendirmektedir. Türkçelerini geliştirmek için Türk kültürüyle iç içe olmaya, okuma kitaplarına ve orta düzey Türkçe kurslarına ihtiyaç duymaktadırlar. Türkçe öğrenenlerin artması için Türk kültürünü tanıtan etkinliklerin yapılmasını, her seviyedeki okullarda Türkçe dersleri açılmasını önermektedirler.

Anahtar Kelimeler: yabancı dil olarak Türkçe, yaşam boyu eğitim, üçüncü yaş üniversitesi, Edinburgh.

\section{Turkish as a Foreing Language in Life Long Learning Courses (Edinburg University of Third Age Sample)}

Abstract: The aim of this study is to determine why foreingers learn Turkish as a foreing language in Edinburgh University of Third Age, what they need to improve their Turkish, which language skills they want to improve, what they think about Turkish and what they suggest us to increase Turkish learners as a foreing language.

This research is a case study. The data was obtained through semi-structured interviews and observations. The descriptive analysis technique was used to analyze the data. The sample of study is Edinburgh University of Third Age.

The group's learning Turkish objective is to communicate with Turkish people. Grup members considered Turkish as being a difficult language To develop their Turkish they need to be intertwined with Turkish culture, and they need reading books and intermediate level Turkish courses. To increase Turkish learners they suggest making social activities promoting Turkish culture, and opening Turkish courses in schools at all levels.

Key Words: Turkish as a foreing language, life long learning, university of third age, Edinburgh. 
Serpil ÖZDEMiR

\section{GíRiş}

Dünyadaki ilk üçüncü yaş üniversitesi 1973'te Fransa'da Toulouse üniversitesine bağlı olarak kurulmuştur ${ }^{1}$. Günümüzde Amerika ve Avrupa'da çok yaygın olan üçüncü yaş üniversitelerinde el sanatlarından akademik konulara uzanan çeşitlilikte bilgiler verilmektedir. "Öğrenmek için asla geç değil" sloganını benimseyen İngiltere Üçüncü Yaş Üniversitesi, emeklilik dönemindeki bireylerin tamamına açıktır. Katılımcıların sadece öğrenme zevki için buluştukları, üyelerin hem öğretmen hem de öğrenci oldukları bu eğitim ortamında dersler kütüphanelerde, evlerde veya okullarda yürütülmektedir. Birleşik Krallık'ta 363 binden fazla kişi bu kurslardan yararlanmaktadır ${ }^{2}$. Türkiye'de kurulan ilk üçüncü yaş üniversitesi ise Heredot Üçüncü Yaş Akademisidir. 2010'da Bodrum'da kurulan bu akademinin 300 üyesi bulunmaktadır ${ }^{3}$.

Birinci yaş dönemi okullarda devam eden eğitim yıllarını, ikinci yaş dönemi meslek hayatı ve çocukların büyütülmesi sürecini, üçüncü yaş dönemi ise emeklilik sürecini kapsamaktadır. Üçüncü yaş üniversiteleri boş zamanı olan, kendini geliştirmek isteyen yetişkinlere sunduğu çeşitli kurs olanaklarıyla bireylerin yeni şeyler öğrenmesine ve sosyalleşmesine katkıda bulunmaktadır.

Üçüncü yaş üniversitelerindeki kurslarda Türkçe öğrenen yabancılar, Türkçenin bir dünya dili olmasına katkı sağlamaktadırlar. Bu nedenle üçüncü yaş üniversitelerinde Türkçe öğrenenlerin öğrenme nedenlerini, Türkçelerini geliştirmek için nelere ihtiyaç duyduklarını, hangi dil becerilerini geliştirmek istediklerini, Türkçe hakkında düşüncelerini ve Türkçeyi yabancı dil olarak öğrenenlerin artması için yapmamı gerekenler konusunda önerilerini öğrenmek önemlidir. Ayrıca bu araştırma, yabancı dil olarak Türkçe öğretiminde hayat boyu öğrenmeyi ilk defa ele alması bakımından özgündür. Bu bağlamda araştırmanın problem tümcesi “Edinburgh Üçüncü Yaş Üniversitesinde Türkçe öğrenen yabancıların Türkçe öğrenme nedenleri ve Türkçelerini geliştirmek için ihtiyaçları, Türkçe hakkındaki görüşleri ve Türkçe öğrenenlerin artması için önerileri nelerdir?" şeklinde belirlenmiştir. Konu aşağıdaki alt problemler çerçevesinde ele alınmıştır:

Edinburgh Üçüncü Yaş Üniversitesinde Türkçe öğrenen yabancıların;

1. Türkçe öğrenme nedenleri nelerdir?

2. Türkçelerini geliştirmek için nelere intiyaçları vardır?

3. Geliştirmek istedikleri dil becerileri hangileridir?

4. Türkçe hakkında görüşleri nelerdir?

5. İskoçya'da Türkçe öğrenenlerin pek az olmasına ilişkin görüşleri ve Türkçe öğrenmenin yaygınlaşması için önerileri nelerdir?

\section{YÖNTEM}

Araştırmada nitel araştırma yöntemlerinden durum çalışması kullanılmıştır. Araştırmanın konusu gereği de durum çalışması içerisinden bütüncül tek durum deseni benimsenmiştir. Araştırma verilerinin toplanmasında yarı yapılandırılmış görüşme formundan ve gözlemlerden yararlanılmıştır.

\footnotetext{
${ }^{1}$ https://en.wikipedia.org/wiki/University_of_the_Third_Age\#France

${ }^{2}$ http://www.u3a.org.uk/

${ }^{3}$ http://www.hero3a.com/tr/about-h3a/
} 


\subsection{Evren ve Örneklem}

Araştırmanın evrenini bütün üçüncü yaş akademileri oluşturmaktadır. Araştırmanın örneklemi ise Edinburgh Üniversitesi Üçüncü Yaş Akademisidir. Amaçlı örneklem yöntemlerinden kolay ulaşılabilir durum örneklemesi yöntemiyle bu örneklem seçilmiştir. "Bu yöntemde araştırmacı, yakın olan ve erişilmesi kolay olan bir durum seçer." (Yıldırım ve Şimşek, 2013, s. 141). Araştırmacının 2013-2015 yılları arasında Edinburgh Üniversitesinde Türkçe okutmanı olarak görev yapması nedeniyle Edinburgh örneklemi kolay ulaşılabilir nitelikte bir örneklem olmuştur. Durum çalışmasının en temel amacı bir ya da birkaç durumun derinliğine araştırılmasıdır (Yıldırım ve Şimşek, 2013, s. 83). Örneklem grubu Avrupa'da pek çok benzeri olan üçüncü yaş akademilerinden biridir. Bu nedenle araştırılan durumla ilgili derinlemesine bilgiler elde edilmesi mümkündür. Burada Türkçe öğrenen 6 kişi ile görüşmeler yapılmış ve araştırmacı Ocak-Nisan 2015 döneminde iki haftada bir yapılan ders ortamına katılarak gözlemler yapmıştır, toplam 7 ders gözlenmiştir. Grup üyelerinden biri aynı zamanda gruba Türkçe öğretmektedir. Katılımcılara (K) ilişkin kişisel bilgiler Tablo 1 ve 2'de görülmektedir.

Tablo 1

Grup Üyelerinin Kişisel Bilgileri

\begin{tabular}{|c|c|c|c|c|c|}
\hline & Yaş & Cinsiyet & Eğitim Durumu & $\begin{array}{l}\text { Bildiği Yabancı } \\
\text { Diller }\end{array}$ & $\begin{array}{l}\text { Ne zamandır } \\
\text { Türkçe öğrendiği }\end{array}$ \\
\hline $\begin{array}{l}\text { K1 } \\
\text { Öğretmen }\end{array}$ & 65 & Kadın & Yüksek Okul & $\begin{array}{l}\text { Türkçe, } \\
\text { Fransızca, } \\
\text { İspanyolca }\end{array}$ & 15 yıl \\
\hline K2 & 71 & Kadın & Yüksek Okul & $\begin{array}{l}\text { Türkçe, } \\
\text { Fransızca }\end{array}$ & $2 \mathrm{yıl}$ \\
\hline K3 & 70 & Kadın & Yüksek lisans & $\begin{array}{l}\text { Türkçe, } \\
\text { Fransızca, } \\
\text { Almanca, } \\
\text { Yunanca, } \\
\text { İspanyolca }\end{array}$ & 1 yıl \\
\hline K4 & 65 & Kadın & Doktora & $\begin{array}{l}\text { Fransızca, } \\
\text { Almanca, } \\
\text { İspanyolca, } \\
\text { Türkçe }\end{array}$ & 16 yıl \\
\hline K5 & 65 & Kadın & Lisans & Türkçe & $10 \mathrm{yıl}$ \\
\hline K6 & 76 & Kadın & Lisans & $\begin{array}{l}\text { İspanyolca, } \\
\text { İtalyanca }\end{array}$ & 5 yıl \\
\hline
\end{tabular}

Tablo 1'de görüldüğü gibi araştırmaya katılanların tamamı 65 yaş üstü ve kadındır. Bu durum üçüncü yaş üniversitelerine emeklilerin katılmasının bir sonucudur. Türkçe öğrenen grubun tamamı lise üstü eğitim almışlardır. K5 dışındaki katılımcılar Türkçeden başka en az bir yabancı dil bilmektedirler. Türkçe öğrenme geçmişi 1 ile 16 yıl arasında değişmektedir. Grup üyelerinden $\mathrm{K} 1$ grubun öğretmenidir.

Tablo 2

Katılımcıların Türkiye'de Bulunma Durumu

\begin{tabular}{llll} 
& $\begin{array}{l}\text { Hiç } \\
\text { Türkiye'de } \\
\text { bulundunuz } \\
\text { mu? }\end{array}$ & Ne kadar kaldınız? & \\
\hline K1 & Evet & 20 yıldır 2-4 hafta & Tatil için \\
K2 & Evet & 2 kez 2 hafta & Tatil için \\
\hline
\end{tabular}




$\begin{array}{lllll}\text { K3 } & \text { Evet } & 5 \text { kez 1-2 hafta } & \text { Tatil için } & \\ \text { K4 } & \text { Evet } & 7 \text { yıl } & \text { Eğitim vermek için } & \\ \text { K5 } & \text { Evet } & 1992^{\prime} \text { den beri her yıl } 5 \text { ay } & \text { Rüzgâr sörfü için } & \\ \text { K6 } & \text { Evet } & 5 \text { kez 3 gün-3 hafta arası } & \begin{array}{l}\text { Oğlum bir Türk kı } \\ \text { evlendiği için }\end{array} & \\ & & & \end{array}$

Katılımcıların hepsi Türkiye'de bir kezden fazla bulunmuşlardır. Türkiye'ye gelme nedenleri tatil, iş, hobi ve akraba ziyaretidir.

\subsection{Veri Toplama Aracı}

Araştırmanın verileri açık uçlu sorularla ve ders gözlemleri yoluyla elde edilmiştir. Veri toplama aracının hazırlanması aşamasında literatür incelemesi yapılmıs, araştırmanın boyutları belirlenmiş ve bu doğrultuda açık uçlu sorulardan oluşan taslak yazıımıştır. Hazırlanan taslak Avrupa'da yabancı dil olarak Türkçe öğreten 5 okutmana sunularak soruların kapsam geçerliği konusunda görüş bildirmeleri istenmiştir. Türkçe okutmanlarından gelen görüşler doğrultusunda sorular yeniden düzenlenmiştir. Araştırmaya katılacak grubun Türkçe düzeyi soruları anlamaya uygun olmayabilir düşüncesiyle sorular İngilizceye çevrilmiştir. Edinburgh'ta Türklere yeminli tercümanlık hizmeti veren iki Türk kökenli İngilizce öğretmeni tarafından dilin açıkça anlaşılır olması bakımından sorular incelenmiş ve gerekli değişiklikler yapılarak görüşme formuna son hali verilmiştir. Grup üyesi olmayan ve Türkçe öğrenen 4 kişiye görüşme formu uygulanmış, sorularda anlaşılmayan bir durum olmadığı görülmüştür. Veri toplama aracı iki bölümden oluşmaktadır. Birinci bölümde cinsiyet, yaş, eğitim durumu, Türkiye’ye daha önce gidip gitmedikleri, gittilerse hangi amaçla ziyaret ettikleri ve Türkçeyi ne kadar süredir öğrendikleriyle ilgili sorular bulunmaktadır. İkinci bölümde araştırmanın alt problemlerine yanıt arayan açık uçlu 5 soru bulunmaktadır.

"Durum çalışmalarında genellikle birden fazla veri toplama yöntemi işe koşulur; bu yolla zengin ve birbirini teyit edebilecek veri çeşitliliğine ulaşılmaya çalışılır." (Yıldırım ve Şimşek, 2013, s. 83). Araştırma sonuçlarının güvenilir olması açısından ders gözlemleri yapılmıştır. Gözlem sonuçları diğer verilerin yorumlanmasında kullanılmıştır. Son olarak araştırma raporu grup üyeleriyle paylaşılarak görüşlerine sunulmuştur, katılımcılar konunun doğru ve yansız bir şekilde ortaya konduğunu belirtmişlerdir.

Araştırma verileri betimsel analiz yoluyla çözümlenmiştir. Veriler, görüşme formunda kullanılan sorular dikkate alınarak düzenlenmiş ve sistematik biçimde betimlenmiştir. Grup üyelerinin görüşlerini yansıtmak için doğrudan alıntılara da yer verilmiştir. Durumun daha iyi anlaşılması için neden-sonuç ilişkileri bakımından bulgular yorumlanmıştır (Yıldırım ve şimşek, 2013, s. 256).

\section{BULGULAR VE YORUMLAR}

Araştırmanın ilk alt problemini belirlemek için "Niçin Türkçe öğreniyorsunuz?" sorusu yöneltilmiştir. Katılımcıların Türkçe öğrenme nedenleri Tablo 3'te görülmektedir.

Tablo 3

Katılımcıların Türkçe Öğrenme Nedenleri

\begin{tabular}{ll}
\hline Türkçe Öğrenme Nedenleri & Katılımcılar \\
\hline Türkiye'yi, Türkleri ve Türkçeyi sevdiğim için & $\mathrm{K} 1, \mathrm{~K} 4, \mathrm{~K} 5$ \\
Türkiye'nin müziğini, mutfağını ve mimarisini daha iyi anlamak için & $\mathrm{K} 1, \mathrm{~K} 3$ \\
Türkiye'deyken Türklerle iletişim kurmak için & $\mathrm{K} 1, \mathrm{~K} 4, \mathrm{~K} 5$ \\
Gelinim Türk, onun ailesiyle iletişim kurmak için & $\mathrm{K} 2, \mathrm{~K} 6$ \\
Eğlenmek için & $\mathrm{K} 3, \mathrm{~K} 4$ \\
\hline
\end{tabular}


Katılımcıların Türkçe öğrenme nedenleri farklılıkla göstermektedir. Türkiye'yi, Türkleri ve Türkçeyi sevdikleri için, Türk gelinlerinin aileleriyle iletişim kurmak için, Türkiye'nin mimarisini, müziğini ve mutfağını daha iyi anlamak için ve eğlenmek için Türkçe öğrenmektedirler.

K1 grubun aynı zamanda Türkçe öğretmenidir. 20 yıldır Türkiye'ye her yaz tatile gittiğini belirten K1, Türkleri ve Türkiye'yi çok sevmektedir ve adeta gönüllü kültür elçisi gibi yaşamaktadır. Türkiye'ye ve Türklere duyduğu sevgi onu Türkçe öğrenmeye yöneltmiştir. "Her yıl aynı yere gidiyorum, burası bir aile işletmesi, beni aileden biri sayıyorlar. Bana yenge diyorlar. Onları çok seviyorum. Türkçenin sesi bana çekici geliyor. Onları kendi dillerinde anlamak hoşuma gidiyor." (K1).

K4 7 yıl Türkiye'de çalışmıştır ve K5 23 yıldır her yıl 5 ayını Türkiye'de geçirmektedir. Türkiye'de geçen uzun süreler sonucunda Türkiye'ye, Türklere ve Türkçeye karşı olumlu tutumlar geliştirmişlerdir. Türkleri "çok cömert ve sıcakkanlı insanlar" (K4 ve K5) olarak tanımlamaktadırlar. "Edinburgh'a döndügümüzde Türkiye'yi, sıcak havayı, sıcakkanlı insanları ve lezzetli yemekleri özlüyoruz. Türkler çok güzel ingilizce konuşuyor ama siz onların dilinde konuşursanız çok mutlu oluyorlar." (K5).

K4, 1988-93 ve 1997-99 yılları arasında İstanbul'da özel bir firmada eğitmen olarak görev yapmıştır. Bu süreçte günlük hayatı devam ettirmek ve Türklerle iletişim kurmak ihtiyacı kendisini Türkçe öğrenmeye yönelten ilk neden olmuş. Ancak üzerinden yıllar geçtikten sonra bile Türkçe öğrenmeye devam etmesini Türklere duyduğu sevgi ile açıklamaktadır: "Türkiye'de çok sevimli insanlarla tanıştım, çok güzel anılarım var. Bu nedenle Türkçe öğrenmeyi seviyorum."

Tatil için Türkiye'ye gelen K1 ve K3 Türkiye'nin mimarisini, müziğini ve mutfağını daha iyi anlamak için Türkçe öğrendiklerini belirtmektedirler. Tatile gitmeden önce gidecekleri yerler hakkında bilgi edindiklerini, gezilerinin böylece daha anlamlı olduğunu dile getiren K1 ve K3 Türkiye'ye sık sık gittiklerini Efes'ten Van'a kadar pek çok değişik yeri gezdiklerini dile getirmektedirler. Bu gezilerde entelektüel birikimlerini arttırmak ve Türkiye'yi daha iyi tanıyabilmek için Türkçe öğrenmektedirler: "Türkiye'ye her gidişimde ayrı bir özelliğini keşfediyorum. Her bölgesinde değişik müziği, güzel yemekleri ve farklı mimarisi var. Bu çeşitliliği anlamak için Türkçe öğreniyorum." (K3).

Katılımcılardan Türkiye'ye sık sık gelenlerin Türklerle iletişim kurma ihtiyacı duyması sonucunda Türkçe öğrendikleri görülmektedir: "1992'den beri her yıl 5 ayı Türkiye'de geçiriyoruz. Başlangıçta rüzgâr sörfü için Türkiye'ye gidiyordum, ama artık Bodrum'da bir evimiz var, biz aynı zamanda Bodrumluyuz. Burada birçok insan Ingilizce biliyor, daha az eğitimli olup ingilizce bilmeyen Türklerle iletiş̧im kurmak ve günlük hayatı sürdürebilmek için 10 yıldır Türkçe öğrenmeye devam ediyorum." (K5).

K2 ve K6 gelinleri Türk olduğu için Türkçe öğrenmeye başladıklarını belirtmektedirler. Aslında gelinler çok iyi İngilizce konuşmaktadır, ancak onların aileleri İngilizce bilmediği için K2 ve K6 Türkçe öğrenmeye çalışmaktadırlar. "Gelinim Türk, o Ingilizce biliyor, ama onun ailesi ingilizce bilmiyor. Onlarla konuşabilmek için önce bir kitap ve cd aldım, sonra da yetişkinler için kurslara katıldım." (K6).

Avrupa kültüründe eğlenmek amacıyla öğrenmeyi sürdürmek çok yaygın bir anlayıştır. Ortak zevki ve ilgileri olan insanlar bir araya gelip eğlenceli aktivitelerle yeni şeyler öğrenirken sosyal bir çevre de edinmektedirler. Zaten üçüncü yaş akademileri hala öğrenme heyecanı taşıyan, emekli ve boş zamanı bol olan bireylerin bir araya geldikleri ortamlardır. K3 eğlenmek 
için Türkçe öğrendiğini belirtmektedir: "Başka bir kültürü tanımak benim için eğlenceli bir uğraş."

Araştırmanın ikinci alt problemi hangi dil becerilerini geliştirmeyi istediklerini belirlemeye yöneliktir. Katılımcıların geliştirmek istedikleri Türkçe dil becerileri Tablo 4'te görülmektedir.

Tablo 4

Katılımcıların Geliştirmek istedikleri Dil Becerileri

\begin{tabular}{ll}
\hline Geliştirmek i̇stenen Dil Becerileri & Katilımcllar \\
\hline Konuşma & $\mathrm{K} 1, \mathrm{~K} 2, \mathrm{~K} 3, \mathrm{~K} 4, \mathrm{~K} 5, \mathrm{~K} 6$ \\
Kelime öğrenme & $\mathrm{K} 1, \mathrm{~K} 2, \mathrm{~K} 3, \mathrm{~K} 4, \mathrm{~K} 5, \mathrm{~K} 6$ \\
Dinleme & $\mathrm{K} 2, \mathrm{~K} 3, \mathrm{~K} 6$ \\
Dilbilgisi & $\mathrm{K} 1, \mathrm{~K} 3$ \\
\hline
\end{tabular}

Grubun tamamı konuşma becerisi ve kelime öğrenme becerisini geliştirmek istediklerini belirtmiştir. Konuşma onlar için Türklerle iletişim kurmanın en temel yoludur. Aynı zamanda kelime hazinesini geliştirerek kendilerini daha iyi ifade etmek istemektedirler. K4 ve K5 uzun süre Türkiye'de bulundukları için Türkçe anlamada sıkıntı yaşamadıklarını ama konuşmakta zorlandıklarını belirtmektedirler: "Konuşurken sözcükleri tam lazım olduğu zaman hatırlayamıyorum." (K4). "Türkçenin farklı bir söz dizimi var, her şeyi tersinden düşünüp söylemek çok zor. Aynı cümleyi bir Türk söylediğinde aslında çok kolaymış, diyorum." (K5). Grup üyeleri, daha çok kelime öğrendikçe sadece konuşma değil dinleme becerisinin de geliştiğinin farkındadır: "Önceleri Türkler birbirini nasıl anlayabiliyor, diye düşünüyordum. Sonra fark ettim ki yeni kelimeler öğrendikçe ben de onları anlayabiliyorum." (K2).

Yapılan gözlemlerde grubun Türkçe seviyesinin aynı olmadığı görülmüştür. Bu durum, geliştirmek istedikleri becerilerde de farklı talepleri ortaya çıkarmaktadır.

Dinleme becerisini de geliştirmek istediklerini belirten K2, K3 ve K6 Türkçe öğrenmeye başlama geçmişi ve Türkiye'de bulunma süreleri diğerlerinden daha az olan katılımcılardır. Bu nedenlerle Türkçede duydukları konuşmaları anlamakta daha fazla güçlük çekmektedirler.

Dilbilgisi becerisini geliştirmeyi önemli bulan K1'e göre "Dilin yapısını bilmeden o dili konuşabilmek Türkiye'den uzakta yaşayan insanlar için kolay değildir." Bu anlayışı nedeniyle Türkçe öğretirken Türkçenin grameri hakkında bilgiler vermektedir. Özellikle yeni ve anadilden çok farklı bir dil öğrenme söz konusu olduğunda o dilin yapısı hakkında fikir sahibi olmak önemlidir. K3 Türkçe öğrenmeye 1 yıl önce başlamıştır bu nedenle Türkçenin dilbilgisini öğrenmeye ihtiyaç duymaktadır.

Araştırmanın üçüncü alt problemi Türkçelerini geliştirmek için nelere ihtiyaç duyduklarını belirlemeye yöneliktir. Bulgular Tablo 5'te görülmektedir.

Tablo 5

Katılımcıları Türkçelerini Geliştirmek Iç̧in intiyaçları

\begin{tabular}{ll}
\hline $\begin{array}{l}\text { Türkçelerini Geliştirmek İçin Duyulan } \\
\text { Ihtiyaçlar }\end{array}$ & Katılımcılar \\
\hline Orta düzey Türkçe kursu & $\mathrm{K} 1, \mathrm{~K} 4, \mathrm{~K} 5, \mathrm{~K} 6$ \\
Türk arkadaş & $\mathrm{K} 1, \mathrm{~K} 2, \mathrm{~K} 4, \mathrm{~K} 5, \mathrm{~K} 6$ \\
İyi İngilizce konuşan Türk öğretmen & $\mathrm{K} 1, \mathrm{~K} 2, \mathrm{~K} 4, \mathrm{~K} 5, \mathrm{~K} 6$ \\
Türkçe okuma kitapları & $\mathrm{K} 1, \mathrm{~K} 2, \mathrm{~K} 5, \mathrm{~K} 6$ \\
\hline
\end{tabular}

Grup üyelerinin çoğu orta düzey Türkçe kursuna ih ihtiyaç duyduklarını belirtmişlerdir. Yukarıda da belirtildiği gibi kursiyerlerin Türkçe öğrenmeye başladıkları süre 1 ile 16 yıl arasında değişmektedir. Temel düzeyde Türkçe bilen grup üyeleri orta düzeyde bir kursa ihtiyaç duymaktadırlar, ancak Edinburgh'ta orta düzey Türkçe derslerine yönelik kurs hiçbir zaman açılmamıştır. K1 ve K4 her fırsatta Türkçe kurslarına katıldıklarını ama kurslar temel düzeye 
yönelik olduğu için Türkçelerini geliştirmediklerini belirtmektedirler. "Her bulduğum Türkçe kursuna katıldım ama bu kurslar sadece bildiklerimi unutmamamı sağladı. Türkçemi geliştirmek için orta ve daha ileri seviyede kursa ihtiyacım var." diyen K1 grubun öğretmeni olarak daha ileri seviyede Türkçe bilmeye intiyacı olduğunu ama kurs açılmadığı için öğrendiklerini de unuttuğunu belirtmektedir.

Grup üyeleri, Türkçelerini geliştirmek için Türk arkadaşa ihtiyaç duyduklarını belirtmektedirler. Ingilizcenin ana dil olarak konuşulduğu bir toplumda, zaten sınırlı olan Türkçelerini canlı tutabilmek ve geliştirebilmek için Türklerle arkadaşlık yapmak istemektedirler: "En yararlısı Türk arkadaş olurdu, Edinburgh'ta Türklerle konuşmak isterdim." (K6). Grup üyelerinin hepsinin Türk kültürüne ve yemeklerine hayran olduğu gözlenmiştir. Türklerle arkadaşlık yaparken Türk kültürünü de yaşayabilecekleri nitelikte bir arkadaşlık istediklerini belirtmektedirler. "Örneğin birlikte Türk filmi seyretmek, bir Türk yemeğini birlikte yapmak, birlikte Türk kahvesi içmek, önceden belirlediğimiz bir konuda konuşmak ne iyi olurdu." diyen K5 böyle etkinlikler yapan bir Türk grubu varsa kendilerini haberdar etmemi istemiştir.

İyi İngilizce konuşan Türk bir öğretmen ihtiyacının da oldukça fazla olduğu görülmektedir. Türk öğretmenin bu kadar çok istenmesinin nedenini K1 "Dilbilgisi ve telaffuz hatalarımı düzelterek beni daha çok Türkçe konuşmak için cesaretlendirebilir." şeklinde açıklamaktadır. K2 ve K6 ise "Modern Türkçe ifadeleri güncel olarak, Türkiye'de konuşulduğu gibi öğrenebilmek için." Türk öğretmene ihtiyaç duymaktadırlar.

Tablo 5'te grup üyelerinin Türkçe okuma kitaplarına da ihtiyaç duydukları görülmektedir. İhtiyaç duyulan kitaplar roman, öykü, şiir gibi otantik okuma malzemeleridir. Bu tür kitapların İngilizce çevirisiyle birlikte olmasının iyi bir gelişim malzemesi olacağını düşünmektedirler: "Roman, öykü, şiir gibi Türkçenin orijinal eserlerini okumak gelişimime çok yardım eder. Doğal olarak ingilizcesiyle birlikte olursa daha çok yararlanabilirim." (K6). Ancak bu kitapların seviyeye uygun olması da önemlidir. K5 "Sadece sınırlı kelime hazinesi varsa." Türkçe kitap okuyarak Türkçesini geliştirmek istediğini belirtmektedir.

Araştırmanın dördüncü alt problemi katılımcıların Türkçe hakkında ne düşündükleri ile ilgilidir. Kendi dillerinden oldukça farklı bir yapısı olan Türkçeyi nasıl değerlendirdikleri ile ilgili bulgular Tablo 6'da görülmektedir.

Tablo 6

Katılımcıların Türkçe Hakkında Görüşleri

\begin{tabular}{ll}
\hline Katılımcıların Türkçe hakkında Görüşleri & Katılımcılar \\
\hline Zor bir dil & $\mathrm{K} 1, \mathrm{~K} 2, \mathrm{~K} 3, \mathrm{~K} 6$ \\
Avrupa dillerinden daha kolay & $\mathrm{K} 4$ \\
Hem kolay hem zor & $\mathrm{K} 5$ \\
Mantıklı bir dil & $\mathrm{K} 1, \mathrm{~K} 4, \mathrm{~K} 5$ \\
Hoş sesi olan bir dil & $\mathrm{K} 1, \mathrm{~K} 5, \mathrm{~K} 6$ \\
\hline
\end{tabular}

Grup üyelerinin dördü Türkçeyi zor bir dil olarak değerlendirmektedir. Türkçenin "ingilizceden yapısal farklııkları oldukça çok." (K1), olduğu için Türkçeyi zor bulmaktadırlar.

Grup üyelerinden sadece biri Türkçeyi Avrupa dillerinden daha kolay bir dil olarak değerlendirmektedir. Bunun nedeni ise "Cinsiyet, tanımlıklar, düzensiz fiiller yok; telaffuz düzenli." (K4) şeklinde belirtilmiştir.

Grup üyelerinden K5 Türkçeyi hem kolay hem zor bir dil olarak değerlendirmektedir: "Türkçe nasıl yazılıyorsa öyle okunuyor, telaffuzu kolay ama pek çok ek var, bu Türkçeyi çok zor yapıyor." 
Grup üyeleri Türkçeyi mantıklı bir dil olarak değerlendirmektedir. Bunun nedenleri Türkçenin kurallı bir dil oluşuna ve istisnaların fazla olmamasına bağlanmaktadır: "Bir kuralı öğrendikten sonra her seferinde aynı şekilde kullanabiliyoruz, istisnaları fazla değil." ( K4).

Grup üyelerinin yarısı Türkçeyi hoş sesi olan bir dil olarak değerlendirmektedir. K6 Türkçeyi "çok zarif bir dil" olarak değerlendirmektedir. K1, Türkçenin kulağa hoş gelmesinde ünlü uyumunun bir etkisi olduğunu belirtmektedir: "Ünlü uyumunun başarılı bir disiplin olduğunu ve Türkçeyi dinleyenlerin Türkçeden hoşlanmasını sağladığını düşünüyorum."

Araştırmanın son alt probleminde iskoçya'da Türkçe öğrenenlerin pek az olmasına ilişkin katılımcıların görüşleri ve Türkçe öğrenmenin yaygınlaşması için önerileri belirlenmiştir. İskoçya'da Türkçe öğrenenlerin pek az olmasına ilişkin görüşler Tablo 7'de, Türkçe öğrenmenin yaygınlaşması için öneriler Tablo 8'de verilmiştir.

Tablo 7

Katılımcıların İskoçya'da Türkçe Öğrenenlerin Pek Az Olmasına ilişsin Görüşleri

\begin{tabular}{ll}
\hline İskoçya'da Türkçe Öğrenenlerin Pek Az Olmasının Nedenleri & Katılımcılar \\
\hline Türkçenin okullarda öğretilmemesi & $\mathrm{K} 1, \mathrm{~K} 3, \mathrm{~K} 6$ \\
Türkçenin zor bir dil olarak algılanması & $\mathrm{K} 1, \mathrm{~K} 6$ \\
Türkçenin Arapça, Çince kadar kullanılabilir dil bir dil olmaması & $\mathrm{K} 4, \mathrm{~K} 6$ \\
Türklerin İngilizce konuşmaktan hoşlanması & $\mathrm{K} 1, \mathrm{~K} 2, \mathrm{~K} 5$, \\
Türkiye'ye sık sık gitmemek & $\mathrm{K} 1, \mathrm{~K} 3, \mathrm{~K} 4, \mathrm{~K} 6$ \\
İngilizlerin dil öğrenmeyi sevmemesi & $\mathrm{K} 1, \mathrm{~K} 3, \mathrm{~K} 4$ \\
\hline
\end{tabular}

İskoçya'da Türkçe öğrenenlerin sayıca az olmasıyla ilgili olarak "Türkçenin okullarda öğretilmemesi, zor bir dil olarak algılanması, geniş bir kullanım alanı olmadığının düşünülmesi, Türklerin İngilizce konuşmaktan hoşlanması, Türkiye'ye sık ziyaretler yapmamak ve İngilizlerin dil öğrenmeyi sevmemesi" gibi nedenler belirlenmiştir.

Türkçe ilköğretimden itibaren okullarda okutulmadığı için İskoçlar okullarda okutulan diğer dilleri öğrenmeyi tercih etmektedirler: "Türkçe iskoç okullarında öğretilmiyor, fakat Fransızca, ispanyolca ve Almanca bizim okullarımızda çok yaygın. Bu nedenle insanlar okuldan ayrıldıktan sonra da bu dilleri öğrenmeye devam ediyor." (K1).

Türkçenin zor bir dil olarak algılanması dil öğrenmek isteyenleri diğer dillere yöneltmektedir. Ancak Arapça ve Çincenin de zor diller olarak bilindiğini hatırlattığımızda ise "Türkiye ile siyasi ve ekonomik işbirliği az olduğu için Türkçenin Arapça, Çince kadar kullanılabilir dil bir dil olmadığı" (K6) belirtilmektedir. Siyasi ve ekonomik işbirliği öğrenilen dile kullanım alanları yaratmaktadır. "Öğrendiğiniz dili kullanabileceğiniz bir alan yoksa öğrenmeye harcanacak çaba için pek az sebep vardır." (K5).

Grup üyelerinin yarısı Türkler İngilizce konuşmaktan hoşlandığı için İskoçların Türkçe öğrenmeye gerek duymadıklarını belirtmektedir. İskoçya'da karşılaştıkları Türkler İngilizce konuşmaktadır, ortak bir iletişim dili olduğu için Türkçe öğrenmeye gerek kalmamaktadır. Hatta Türkiye'de bile pek çok insanın çok güzel İngilizce konuştuğunu belirtmektedirler. "Türkiye'ye giden pek çok ziyaretçi çalışanların Ingilizce konuştuğu resort otellere gidiyor. Türkçe konuşmaya çalışsak bile bizim Türkçemiz iyi olmadığı için konuşma ingilizce devam ediyor." ( $\mathrm{K} 5)$.

Grup üyelerinin çoğu İskoçya'da Türkçe öğrenenlerin az olmasını Türkiye'ye sık sık gitmeme nedenine dayandırmaktadırlar: "Türkiye'ye sık sık gitmiyorsanız, Avrupa dilleri daha kullanışı." (K4). Turizmin dil öğrenmede güçlü bir neden olduğu görülmektedir. Tatil için Avrupa ülkelerinin seçilmesi o ülkelerin dilinin öğrenilmesi ile sonuçlanmaktadır: "Pek çok insan kendi ülkesine en yakın ülkelerde tatil yapıyor. Insanlar başka bir dili öğrenmeyi seçtiklerinde genellikle düzenli olarak ziyaret edecekleri ülkenin dilini seçiyorlar." (K1). 
Grup üyelerinin yarısı İngilizlerin dil öğrenmeyi sevmemeleri nedeniyle Türkçe öğrenenlerin az olduğunu belirtmektedirler. Dünyanın her yerinde İngilizce ile iletişim kurabilmeleri İngilizleri dil öğrenmeye yöneltmemektedir: "ingilizler dil öğrenmeyi sevmez, zaten dünyanın her yerinde kendi dilleriyle iletişim kuracak birini buluyorlar." (K3). gelmektedir.

Bu durumda İskoçya'da Türkçe öğrenmenin yaygınlaşması için neler yapılabileceği akla

Tablo 8

Katılımcıların İskoçya'da Türkçe Öğrenmenin Yaygınlaşmasına Yönelik Önerileri

\begin{tabular}{ll}
\hline Öneriler & Katılımcılar \\
\hline Okullarda Türkçenin öğretilmesi & $\mathrm{K} 1, \mathrm{~K} 2, \mathrm{~K} 3, \mathrm{~K} 4, \mathrm{~K} 5$ \\
Kültürel ve sosyal etkinlikler yapılması & $\mathrm{K} 1, \mathrm{~K} 2, \mathrm{~K} 3, \mathrm{~K} 5, \mathrm{~K} 6$ \\
Türk müzik gruplarının ve oyuncuların Edinburgh Festivaline & $\mathrm{K} 1, \mathrm{~K} 3$ \\
konser ve oyunlarıyla katılması & \\
Daha çok Türk yazarın Edinburgh Kitap Festivaline katılması & $\mathrm{K} 1, \mathrm{~K} 2, \mathrm{~K} 5, \mathrm{~K} 6$ \\
Türk Filmleri Festivali yapılması & $\mathrm{K} 1, \mathrm{~K} 6$ \\
\hline
\end{tabular}

Türkçe öğrenmenin yaygınlaşması için katılımcıların önerileri okullarda Türkçe derslerinin yer alması ve Türk kültürünü etkin bir şekilde tanıtarak Türkçeye ilgi uyandırılması yönünde belirginleşmektedir.

İskoçya'da Türkçe öğrenenlerin artması için grup üyeleri her seviyedeki okulda Türkçe öğretilmesinin gereğine inanmaktadırlar: "Okullara ve üniversitelere Türkçe kursları açılması için baskı yapılmalı. Türkçe hem çocuklar hem yetişkinler için her seviyede teşvik edilmeli." (K1). Ancak bunun için birçok resmi süreç olduğunun farkındadırlar. Bu süreçler gerçekleşene kadar Türkçe öğrenme ilgisi yaratabilmek için Türkiye'nin tanınmasını sağlamaya yönelik işlerin yapılmasını önermektedirler.

İskoçya'da Türkçe öğrenenlerin artması için Türk kültürünü tanıtmaya yönelik kültürel ve sosyal etkinlikler yapılması grup üyelerinin çoğunluğunun tavsiyesi olarak dikkat çekmektedir. K5 "Türk konsolosluğu zemininde yapılacak sosyal etkinlikler, iskoçlar ve Türkler arasında daha fazla etkileşimi sağlar." görüşündedir. Türklere ve Türk kültürüne yönelik olumlu bir algının yerleşmesi için kültürel ve sosyal etkinlikleri önemsemektedirler. Kendilerinin en çok etkilendiği kültürel unsurları Türk restoranlarında yedikleri güzel yemekler ve kendilerine her yemekten sonra çay, kahve ikram edilmesi şeklinde belirtmektedirler. Bu nedenle K6'ya göre "Türk restoranlarında buluşmak iyi bir başlangıç olabilir." Yapılan gözlemlerde ders işleme mekânı olarak Türk işletmelerini seçmeleri dikkati çekmiştir. K3 ise Türkiye'de el sanatları tezgâhlarının çok ilgi çekici, Türk halk danslarının eğlenceli olduğunu, bu nedenle "Türk halk dansları veya el sanatları kursları" ile Türk kültürüne ilgi çekilebileceğini belirtmektedir.

Edinburgh her yıl ağustos ayında festival şehrine dönüşmektedir. Şehrin sokaklarında ve bütün önemli mekânlarında dünyanın her yerinden gelen sanatçılar kendi sanatlarını sergilemektedir. Dünyanın her yerinden binlerce insan da bu festivali görmek için Edinburgh'a gelmektedir. Grup üyelerinden K1 ve K3 bu festivale Türk müzik gruplarının ve oyuncuların konser ve oyunlarıyla katılması gerektiğini belirtmektedirler: "Edinburgh festival ofisiyle iletişim kurulmalı. Gösteriler Türkçe veya Ingilizce olabilir fakat toplumun geniş bir kesimine hitap etmesi için oyunların çoğunlukla ingilizce olması tercih edilebilir." (K1). Türk sanatçıların festival performanslarından asıl beklenti Türkçenin öne çıkarılması değil, "Türklerin ne kadar modern insanlar olduklarının anlaşılması" (K3) ile ilgilidir.

Edinburgh'ta yapılan kitap festivali de birçok sanatçının ve ait olduğu kültürün tanıtımı için iyi bir zemin hazırlamaktadır. Orhan Pamuk ve Elif Şafak bu festival aracılığıyla iyi tanınmaktadırlar. Bu nedenle daha çok Türk yazarın Edinburgh Kitap Festivaline katılması grup 
üyelerinin birçoğu tarafından önerilmektedir. Ancak kitapların İngilizceye çevrilmiş olması önemlidir: "Yazarın son zamanlarda Ingilizce yayınlanmış bir kitabı varsa Kitap Festivali yazar için satışla sonuçlanır, aynı zamanda Türkiye'ye ve Türklere ilgiyi arttırır." (K2).

Türk Filmleri Festivali yapılması da grup üyelerinin ilgi çekici önerilerinden biridir. Londra'da Türk Filmleri Festivali yapılmaktadır. Grup üyeleri sadece Türk filmlerini izlemek için Londra'ya gittiklerini belirtmektedirler. Filmlerde Türk kültürüne ait pek çok unsurun bulunması nedeniyle Türk filmlerinin iyi bir tanıtım aracı olacağını belirtmektedirler: "Filmlerde Türkiye'de yaşadığımız şeylere benzer şeyler görmek hoşuma gidiyor. Türk kültürüne ait çok şey görmek mümkün oluyor." (K1).

\section{SONUÇ, TARTIŞMA VE ÖNERILER}

$\mathrm{Bu}$ araştırma üçüncü yaş akademilerinde Türkçe öğrenenlerin Türkçe öğrenme nedenlerini ve Türkçelerini geliştirmek için ihtiyaçlarını belirlemek amacıyla yapılmıştır.

Araştırma nitel yöntemlerden bütüncül tek durum deseniyle yürütülmüştür. Araştırmanın örneklemi Edinburgh Üçüncü Yaş Akademisinde Türkçe öğrenen 6 kişilik gruptur. Araştırmanın verileri yarı yapılandııılmış görüşme formu ve 7 dersin gözlenmesiyle elde edilmiştir.

Araştırma sonucunda grubun Türkçe öğrenme nedenleri; Türkiye'yi, Türkleri ve Türkçeyi sevmek, Türk gelinlerinin aileleriyle iletişim kurmak, Türkiye'nin mimarisini, müziğini ve mutfağını daha iyi anlamak ve eğlenmek olarak belirlenmiştir. Bu sonuçlar "bireysel ilgi ve intiyaçlar" (Çangal, 2013, s. 42) çerçevesinde Türkçeyi öğrendiklerini göstermektedir.

Türkçe öğrenme nedenleri üzerine yapılan çalışmalar öğrenenlerin kişisel özelliklerine ve yaşadıkları ülkenin Türkiye'yle olan tarihi, kültürel, ekonomik ve siyasi ilişkilerine bağlı olarak farklı nedenler ortaya koymaktadır. Arnavutluk'ta eğitim (Balaban, 2014), Kazakistan'da Türki cumhuriyetlerle daha rahat iletişim kurabilmek ve Türkiye-Kazakistan arasındaki sosyal, siyasal, kültürel, ekonomik ilişkiler (Yılmaz ve Düzdağ, 2008), Ankara Üniversitesi TÖMER'de eğitim gören Araplar için iyi bir iş bulabilmek (Koçer, 2013) Türkçe öğrenilmesinde başlıca nedenler olarak öne çıkmaktadır. Bu araştırmaya katılanlar 60 yaş ve üstü olup emeklilik dönemlerindedirler. Bu nedenle iş, ticaret yapma veya eğitimsel amaçlar görülmemektedir.

Grubun geliştirmek istediği dil becerileri konuşma, kelime öğrenme, dinleme ve dilbilgisi olarak belirlenmiştir. Grup üyelerinin gündelik iletişim için gerekli becerileri öne çıkardıkları söylenebilir. Grubun tamamının Türklerle konuşarak iletişim kurmayı ve kelime öğrenerek kendilerini daha iyi ifade etmeyi istediği görülmüştür. Grubun Türkçe seviyesi eşit olmadığı için geliştirmek istedikleri becerilerde farklı talepler görülmektedir. Türkçe öğrenmeye başlama geçmişi ve Türkiye'de bulunma süreleri diğerlerinden daha az olan katılımcılar için dinleme becerisini geliştirmek önemlidir. Türkçeyi yeni öğrenen yabancıların dinleme becerisini en zor beceri olarak gördüŭünü gösteren araştırmalar vardır (Melanlıoğlu, 2014; Yağmur Şahin vd., 2013). Konuşma ve dinleme, sözel iletişim becerileridir. Elbette bilinen kelimelere dayalı olarak gelişmesi beklenir. "iki becerinin ortak alanı seslerin doğru algılanması ve üretilmesini içeren ses eğitimidir. (...) Seslerin üretilmesinin yanı sıra onların bir araya geldikleri kelimeler, (...) vurgular, tonlamalar konusunda da eğitim almak gerekir." (Köksal ve Dağ Pestil, 2012, s. 213). Bu sonuçlar grubun sözlü dil becerisi geliştirme amacıyla uyumludur.

Grubun öğretmeni, Türkiye'den uzakta oldukları için dilin yapısını bilmeden o dili konuşabilmenin zor olduğunu düşünmektedir. Bu nedenle dilbilgisi becerisini önemli bulmaktadır. Ancak öğrencilerden sadece Türkçe öğrenme geçmişi en az olan grup üyesi, Türkçenin dilbilgisini öğrenmeye ihtiyacı olduğunu belirtmiş̧ir. Uzun yıllardır Türkçe öğrenen diğer üyeler için dilbilgisi geliştirme isteği söz konusu değildir. 
Grup üyelerinin Türkçelerini geliştirmek için orta düzey Türkçe kursuna, Türk arkadaşa, iyi İngilizce konuşan Türk bir öğretmene ve Türkçe okuma kitaplarına ihtiyaç duydukları belirlenmiştir. Grup üyelerinin 1 ile 16 yıl arasında değişen uzun bir Türkçe öğrenme geçmişi vardır. Ancak Edinburgh'ta orta düzey Türkçe derslerine yönelik bir kurs hiçbir zaman açılmamıştır. Bu nedenle kurslara yeni bir şey öğrenmek için değil, Türkçelerini unutmamak için katılmaktadırlar. Grubun öğretmeninin daha ileri seviyede Türkçe bilmeye ihtiyacı olduğunu ama kurs açılmadığı için öğrendiklerini de unuttuğunu belirtmesi yabancı dil olarak Türkçe öğretimi açısından düşündürücüdür.

Grup üyelerinde Türkçelerini canlı tutabilmek ve geliştirebilmek için Türklerle arkadaşılı yapmak isteği çok güçlüdür. Grup üyelerinin hepsi Türk kültürüne ve yemeklerine hayrandır. Türklerle arkadaşık yaparken Türk kültürünü de yaşayabilecekleri nitelikte bir arkadaşlık istemektedirler. Birlikte Türk filmi seyretmek, bir Türk yemeğini birlikte yapmak, birlikte Türk kahvesi içmek, önceden belirlenen bir konuda konuşmak istemektedirler. Bu tespitler dil ile kültür ilişkisini ve yaşayarak öğrenmeyi vurgulaması bakımından önemlidir. "Dil ve kültür arasında etkileşimli bir ilişki her zaman vardır: Biri olmadan diğeri olamaz." diyen Jiang $(2000$, s. 332) dil ve kültürü havuz benzetmesiyle açıklar: Toplumu yüzme havuzu olarak düşünürsek dil yüzme becerisi ve kültür sudur. Her ikisi de bulunduğunda insanlar iyi yüzer, yani iletişim başarılı bir şekilde gerçekleşir.

Grubun iyi İngilizce konuşan Türk bir öğretmene intiyacının olduğu belirlenmiştir. Grubun öğretmeni B1 düzeyinde Türkçe bilmektedir. Türk öğretmenle çalışınca dilbilgisi ve telaffuz hatalarını düzeltip daha çok Türkçe konuşmak için cesaretleneceğini belirtmektedir. Grup üyeleri ise Türkçeyi Türkiye'de konuşulduğu gibi öğrenebilmek için Türk öğretmene ihtiyaç duymaktadırlar.

Grup üyelerinin roman, öykü, şiir gibi İngilizceye de çevrilmiş Türkçe okuma malzemelerine ihtiyaç duydukları belirlenmiştir. Bu kitapların seviyeye uygun olması da önemlidir. Sınırlı kelime hazinesi olan kitaplar okuyarak Türkçelerini geliştirmek istemektedirler. Bu durum Türkçenin temel söz varlığının belirlenmesine yönelik çalışmaların ve seviyeye göre düzenlenmiş okuma kitaplarının önemini göstermektedir. Türkçe için farklı seviyelere uygun okuma kitaplarının maalesef pek az örneği vardır. Dilset yayınlarının A1, A2 seviyeleri için yardımcı okuma kitapları vardır. Ancak bu kitaplar çocuklara yöneliktir ve edebi bir içerik söz konusu değildir. Yunus Emre Enstitüsünün de A1, A2 seviyesine yönelik 12 kitaptan oluşan hikâye serisi bulunmaktadır. Fakat bu örnekler henüz İngilizce için hazırlanmış farklı seviyelere ve yaş gruplarına uygun okuma kitapları ile kıyaslanabilecek durumda değildir.

Grup üyelerinin Türkçe hakkındaki değerlendirmeleri Türkçenin zor bir dil olduğu yönündedir. Türkçenin zor olmasının nedenleri İngilizceden yapısal farklılıklarının çok olması ve pek çok ek kullanılmasıdır. Bununla birlikte grup üyelerinden biri Türkçede cinsiyet, tanımlıklar, düzensiz fiiller olmadığı için ve Türkçenin telaffuzu düzenli olduğu için Türkçeyi Avrupa dillerinden daha kolay bir dil olarak değerlendirmektedir. Türkçenin yazııldığı gibi okunması dilimizi kolay kılan bir diğer özellik olarak belirtilmektedir. Grup üyeleri Türkçeyi mantıklı bir dil olarak değerlendirmektedir. Bunun nedenleri Türkçenin kurallı bir dil oluşuna ve istisnaların fazla olmamasına bağlanmaktadır. Türkçe hakkında bir diğer değerlendirme ise Türkçenin hoş sesi olan bir dil olduğu yönündedir. Türkçenin kulağa hoş gelmesinde ünlü uyumunun bir etkisi olduğunu belirtmektedirler.

İskoçya'da Türkçe öğrenenlerin sayıca az olmasıyla ilgili olarak "Türkçenin okullarda öğretilmemesi, zor bir dil olarak algılanması, geniş bir kullanım alanı olmadığının düşünülmesi, Türklerin İngilizce konuşmaktan hoşlanması, Türkiye'ye sık ziyaretler yapmamak ve İngilizlerin dil öğrenmeyi sevmemesi" gibi nedenler belirlenmiştir. Türkçe ilköğretimden itibaren okullarda 
okutulmadığı için İskoçlar okullarda okutulan Fransızca, i̇spanyolca ve Almanca gibi dilleri öğrenmeyi tercih etmektedirler.

Türkçenin zor bir dil olarak algılanmasının dil öğrenmek isteyenleri diğer dillere yönelttiği belirlenmiştir. Ancak Arapça ve Çincenin de zor diller olarak bilindiğini hatırlattığımızda ise Türkiye ile siyasi ve ekonomik işbirliği az olduğu için Türkçenin Arapça, Çince kadar kullanılabilir dil bir dil olmadığı ifade edilmiştir. Siyasi ve ekonomik işbirliği öğrenilen dile kullanım alanları yaratmaktadır. Grup üyelerinin Türkiye'yle ilişkisi tatil, gelinlerinin ailesini ziyaret etmek ve Türkiye'de eğitim vermek suretiyle başladığı belirlenmiştir. Dolayısıyla bireysel nedenlerle Türkçe öğrenmektedirler. İskoçya'da Türkçe öğrenmek için toplumsal bir itici güç yoktur. "Türkçenin de öğrenilmesi gereken diller konumuna ulaşması ekonomi, siyaset, turizm, kültür, bilim ve eğitim alanlarında gösterilecek ilerlemelerle de oldukça ilgilidir." (Tok ve Yığın, 2013, s. 134).

Yaptığımız belirlemelere göre Türklerin İngilizce konuşmaktan hoşlanması nedeniyle İskoçlar Türkçe öğrenmeye gerek duymamaktadır. İskoçya'da yaşayan Türkler İngilizce konuşmaktadır, Türkiye'ye geldiklerinde otel çalışanları da İngilizce konuşmaktadır. Ortak bir iletişim dilinin varlığı Türkçe öğrenmeye gerek bırakmamaktadır.

Grup üyelerinin çoğu İskoçya'da Türkçe öğrenenlerin az olmasını Türkiye'ye sık sık gitmeme nedenine dayandırmaktadırlar. Tatil için Avrupa ülkelerinin seçilmesi o ülkelerin dilinin öğrenilmesi ile sonuçlanmaktadır. Sık ziyaret edecekleri ülkenin dilini öğrenmek istedikleri için turizmin dil öğrenmede güçlü bir neden olduğu söylenebilir.

Konuyla ilgili ilginç bir tespit İngilizlerin dil öğrenmeyi sevmemeleri nedeniyle Türkçe öğrenenlerin az olduğudur. Dünyanın her yerinde İngilizce ile iletişim kurabilmeleri İngilizleri dil öğrenmeye yöneltmemektedir.

İskoçya'da Türkçe öğrenenlerin artması için grup üyeleri her seviyedeki okulda Türkçe öğretilmesinin gereğine inanmaktadırlar. Ancak bunun için birçok resmi süreç olduğunun farkındadırlar. Bu süreçler gerçekleşene kadar Türkçe öğrenme ilgisi yaratabilmek için Türkiye'nin tanınmasını sağlamaya yönelik işlerin yapılmasını önermektedirler.

İskoçya'da Türkçe öğrenenlerin artması için Türk kültürünü tanıtmaya yönelik kültürel ve sosyal etkinlikler yapılması yoluyla İskoçlar ve Türkler arasında etkileşimi arttırmak gerektiğine dikkat çekmektedirler. Kültürel ve sosyal etkinlikleri Türklere ve Türk kültürüne yönelik olumlu bir algının yerleşmesi için önemsemektedirler. Kendilerinin en çok etkilendiği kültürel unsurları Türk restoranlarında yedikleri güzel yemekler ve kendilerine her yemekten sonra çay, kahve ikram edilmesi şeklinde belirtmektedirler. Türk restoranlarında buluşmanın iyi bir başlangıç olabileceğini ve Türk halk dansları veya el sanatları kursları ile Türk kültürüne ilgi çekilebileceğini belirtmektedirler.

Edinburgh her yıl ağustos ayında festival şehrine dönüşmektedir. Şehrin sokaklarında ve bütün önemli mekânlarında dünyanın her yerinden gelen sanatçılar kendi sanatlarını sergilemektedir. Dünyanın her yerinden binlerce insan da bu festivali görmek için Edinburgh'a gelmektedir. Grup üyeleri bu festivale Türk müzik gruplarının ve oyuncuların konser ve oyunlarıyla katılması önermektedir. Türk sanatçıların festival performanslarından asıl beklenti Türkçenin öne çıkarılması değil, Türklerin ne kadar modern insanlar olduklarının anlaşılması ile ilgilidir.

Edinburgh'ta yapılan kitap festivali de birçok sanatçının ve ait olduğu kültürün tanıtımı için iyi bir zemin hazırlamaktadır. Orhan Pamuk ve Elif Şafak bu festival aracılığıyla iyi tanınmaktadır. Bu nedenle daha çok Türk yazarın Edinburgh Kitap Festivaline katılması grup 
üyelerinin birçoğu tarafından önerilmektedir. Ancak kitapların İngilizceye çevrilmiş olması önemlidir.

Türk Filmleri Festivali yapılması da grup üyelerinin ilgi çekici önerilerinden biridir. Londra'da Türk Filmleri Festivali yapılmaktadır. Grup üyeleri sadece Türk filmlerini izlemek için Londra'ya gittiklerini belirtmektedirler. Filmlerde Türk kültürüne ait pek çok unsurun bulunması nedeniyle Türk filmlerinin iyi bir tanıtım aracı olacağını belirtmektedirler.

Yapılan araştırma çerçevesinde yurt dışında Türkçe öğrenenlerin artması ve Türkçenin daha iyi seviyede öğrenilmesi için aşağıdaki önerilerde bulunulmaktadır:

1. Yabancı dil olarak Türkçe kursları sadece temel düzeyde kalmamalı, orta düzeyde kurslar da açılmalıdır.

2. Yabancıların Türk kültürünü yaşamalarını ve Türkçeyi Türkiye'de konuşulduğu gibi öğrenmelerini sağlayacak organizasyonlar yapılmalıdır. Bu konuda Türk kültür derneklerinin ve konsoloslukların sorumluluk alması gerektiği düşülmektedir. hazırlanmalıdır.

3. Farklı seviyelere ve yaş gruplarına hitap eden edebi içerikli okuma kitapları

4. Film, kitap, el sanatları ve halk dansları ile ilgili festivaller Türk kültürünü tanıtma ve Türkçeye ilgi uyandırma açısından desteklenmelidir.

\section{KAYNAKLAR}

Balaban, A. (2014). Arnavutluk'ta Türkçe öğretimi ve Arnavutların Türkçe öğrenme sebepleri. Uluslararası Sosyal Araştırmalar Dergisi. 7(33), 625-634.

Çangal, Ö. (2013). Yabancılara Türkçe öğretiminde dil ihtiyaç analizi: Bosna-Hersek örneği. (Yayınlanmamış Yüksek Lisans Tezi). Gazi Üniversitesi, Ankara.

Jiang, W. (2000). The relationship between culture and language. ELT Journal. 54(4), 328-334.

Koçer, Ö. (2013). Program geliştirmenin ilk basamağı: yabancı dil olarak Türkçe öğretiminde ihtiyaç ve durum analizi. Eğitim ve Bilim. 38(169), 159-174.

Köksal, D. ve Dağ Pestil, A. (2012). Yabancı dil olarak Türkçe konuşma öğretimi. A. Kılınç, A. Şahin, (Ed.),Yabancı dil olarak Türkçe öğretimi içinde (s. 213-234). Ankara: Pegem Akademi.

Melanlıoğlu, D. (2014). Perceptions of foreigners about process of learning Turkish. Bartın Üniversitesi Eğitim Fakültesi Dergisi. 3(2), 368-389.

Tok, M. ve Yığın, M. (2013). Yabancı uyruklu öğrencilerin Türkçe öğrenme nedenlerine ilişkin bir durum çalışması. Dil ve Edebiyat Eğitimi Dergisi. 8, 132-147.

Yağmur Şahin, E. ve İşcan, A. vd. (2013). Yabancı dil olarak Türkçe öğrenen öğrencilerin ihtiyaç algıları: betimsel bir durum çalışması. International Journal of Social Science. 6(4), 11851198.

Yıldırım, A. ve şimşek, H. (2013). Sosyal bilimlerde nitel araştırma yöntemleri. Ankara: Seçkin Yayıncilık.

Yılmaz, M. ve Düzdağ, M. M. (2008). Türkiye Türkçesinin önemi ve Kazakistan vatandaşlarının Türkiye Türkçesi öğrenme sebepleri. II. Uluslarası Sosyalbilimciler Kongresi. 22-24 Ekim 2008, Kazakistan. 


\section{SUMMARY}

The aim of this study is to determine why foreingers learn Turkish as a foreing language in Edinburgh University of Third Age, what they need to improve their Turkish, which language skills they want to improve, what they think about Turkish and what they suggest us to increase Turkish learners as a foreing language.

The data was obtained through semi-structured interviews and observations. The descriptive analysis technique was used to analyze the data. The sample of study is Edinburgh University of Third Age.

As a result of this study, it was determined that the objective of this group's learning Turkish was loving Turkey, Turkish and Turks; communicating with Turkish people, understanding Turkey's architecture, music and cuisine. These results indicate that they learned Turkish in the framework of individual interests and needs. Participants in this study are 60 years old and above and retired. Therefore, business, commercial or educational purposes does not appear.

It was defined that they wanted to develop speaking, vocabulary learning listening and grammar skills. Because the group's Turkish level is different, they want to improve different language skills. To develop listening skills are more important for the participants who had been learned Turkish for a long time and had been Turkey for a long term than others. These results are compatible with the purpose of the group's oral language skills development.

The group's teacher believes that, without knowing the structure of the language it is difficult to speak that language because they were far from Turkey. Therefore, she accepts the grammar skill is important. However, only the member of the group learning Turkish history is limited stated that she needed to learn the grammar of the Turkish language.The other members learning Turkish for many years do not wanted to develop the grammar skill.

It was determined that the group's members were need to intermediate level Turkish course, Turkish friend, Turkish teacher who speaks Englih very well and reading books to improve their Turkish. The intermediate Turkish course was never opened in Edinburgh. Therefore, they join Turkish courses not to forget their Turkish. The goup's teacher mentioned that she needed to know further level Turkish but she forgot what she knew because Turkish courses was not opend. This is thought provoking in terms of teaching Turkish as a foreign language

The group members have a very strong desire to make friends with Turkish people to keep alive and develop their Turkish. They are admire the Turkish culture and food. While they do a friendship with Turks, they also want to live in the Turkish culture. they want to watch a Turkish movie, cook a Turkish food, drink Turkish coffee together, and talk about a predetermined topic. These findings are important for highlighting the relationship between language and culture and learning by doing.

It was determined that the group needed a native speaker Turkish teacher who speak English very well. The group's teacher's Turkish level is B1. She prefer a Turkish teacher to correct her grammer and pronunciation mistakes and to get courage speaking Turkish. Group members also prefer a native speaker Turkish teacher to learn Turkish as spoken in Turkey.

It was determined that the group needed Turkish reading materials such as novel, short story and poetry translated into English. It is important that these books are suitable for level. Because they want to improve their Turkish by reading books which have limited vocabulary. This shows the importance of determining the Turkish basic vocabulary and the level organized reading books.

The group considered Turkish as being a difficult language because of its sentence structure being different from English and being an agglutinative language. However, they stated that Turkish was a logical language and had pleasant sound, its vowel harmony having a role in this, and Turkish had regular pronunciation because it did not have gender, articels and irregular werbs unlike European languages.

This study shows a lot of reasons regarding being outnumbered those who learn Turkish in Scotland. These reasons are based on the following: "not being taught Turkish in schools, being 
perceived as a difficult language and thought that there was not a large using area, not making frequent visits to Turkey and not being loved language learning by the British". Because Turkish is not taught in schools from elementary the Scots prefer to learn French, Spanish and German languages which are taught in schools.

The group believes that teaching Turkish is a need in schools at all levels to increase learners in Scotland. However, they aware that there are many formal process for this. Until the formal process ending they suggest doing some things for Turkey's recognition to create interest in learning Turkish.

In this context, to increase Turkish learner abroad and being learnt Turkish in better level the following recommendations are made:

1. Not only basic level, but also intermediate level Turkish courses should be opened.

2. To gain experience Turkish culture and teach Turkish as it spoken in Turkey to foreingers some organizations should be made. In this regard, it is thought that Turkish cultural associations and embassies should take responsibility.

3. Reading books which have literary contents should be prepared to address the different levels and age groups.

4. Some festivals such as movie festivals, book festivals, crafts festivals and folk dance festivals should be supported to introduce the Turkish culture and evoke interest in Turkish. 